\title{
Production of Fermented Milk with Autochthonous Lactobacilli for Newborn Calves and Resistance to the Dairy Farm Conditions
}

\author{
Natalia Cecilia Maldonado and María Elena Fátima Nader-Macías* \\ Centro de Referencia para Lactobacilos (CERELA-CONICET), Chacabuco 145., 4000. San Miguel de Tucumán, Argentina
}

\begin{abstract}
Four different autochthonous calves' strains: Lactobacillus johnsonii CRL1693, L. murinus CRL1695, L. mucosae CRL1696 and $L$. salivarius CRL1702 were evaluated by their resistance and survival to dairy farm conditions and were used to prepare probiotic fermented milk for young calves. The strains were previously isolated from calf's faeces and selected by their beneficial properties. The resistance of the microorganisms to water, colostrum and raw milk was by using those of the environment of a dairy farm. Compatibility assays were performed to know if the strains can be combined in the final fermented product. For the elaboration of fermented milk, different inoculum, incubation times and acidifying capability of the strains were determined and also their survival and the maintenance of beneficial properties during storage at low temperature. Antibiotic resistance profiles were applied to differentiate the strains throughout the experiments. The results indicate that bacteria survive in colostrum $(1,3$ or 5 days after calving) and water for 2 or 4 hours. All the strains grow in raw milk, and were compatible between them. The optimum fermentation time was 8 hours at $37^{\circ} \mathrm{C}$, reaching $3.78 \times 10^{8} \mathrm{CFU} / \mathrm{ml}$ from an inoculum of $3 \times 10^{9} \mathrm{CFU}$ of each strain in sterile milk. Surface properties as auto-aggregative and hydrophobicity patterns were maintained after the process. Bacteria remained viable during 30 days at refrigeration temperature at a concentration of $3.37 \times 10^{7} \mathrm{CFU} / \mathrm{ml}$. The dose suggested is $10 \mathrm{ml}$ of fermented milk prepared at the laboratory and stored at $4^{\circ} \mathrm{C}$ for younger animals. For older calves, a second fermentation in the farm is proposed to reach $3.94 \times 10^{6} \mathrm{CFU} / \mathrm{ml}$. Animal experiments are being performed to determine the efficacy of the fermented milk for diarrhea prevention.
\end{abstract}

Keywords: Fermented milk; Beneficial lactobacilli; Probiotic product; Calves; Storage

\section{Introduction}

The immune system of calves is immature at birth because they do not receive antibodies from their mothers during intrauterine life. After birth, the antibodies are incorporated by colostrum's, supporting the increase of different immunoglobulin's types, IgM, IgA and IgG, which triggers the passive immunity of calves, Colostrum contains cellular components and nonspecific immunological factors [1], is the first postpartum secretion of the cow, and the first food consumed by the newborn, being of main importance for their survival during the first days of life [2].

Neonatal diarrhea is one of the leading causes of death in calves in dairy farms and produce high economic losses to this sector [3]. The use of antibiotics for therapy and prevention is not recommended by the acquired resistance of indigenous microbiota and residues in animal's products [4]. At present, probiotics as novel additive foods for preventing intestinal infections are being commercialize [5]; the use of probiotics is supported by the beneficial characteristics of specific strains, being administered to restore the balance of intestinal microbiota and avoid imbalances that could favor the colonization of pathogenic or potentially pathogenic bacteria [6-8]. Probiotics are defined as "live microorganisms which when administered in adequate amounts confer a beneficial health benefit on the host". Different scientists have reported the efficacy of probiotics in a range of animal's host as calves, pigs and poultry [8,9].

A wide range of publications show the benefits of consumption of milks fermented with beneficial microorganisms, mainly lactic acid bacteria, on human health, $[10,11]$. Fermented dairy products are widely used as a matrix to vehiculize probiotic strains. Nevertheless, the benefits of probiotics products on the host are highly dependent on the specific strain used in the design of the formula, and later complemented by the maintenance of their beneficial properties [12].
Referred to a probiotic product, the lower number of viable cells recommended for daily consumption should be between $10^{8}$ and $10^{11}$ CFU/d [13] to produce a benefit effect on the host, then the product must contain $10^{7}-10^{9}$ colonies forming units $\mathrm{CFU} / \mathrm{g}$ or $\mathrm{ml}[14]$.

In this work, autochthonous strains isolated from calf s faeces and selected by their beneficial properties were evaluated for their survival to dairy farm conditions and were used to elaborate fermented milk for young calves. The effect of different factors as culture conditions, fermentation time, storage and maintenance of the beneficial properties of the strains were also evaluated to support that the number and activity of viable lactobacilli are into the recommended levels in the final product, or in the formula administered to calves.

\section{Materials and Methods}

\section{Microorganism and growth conditions}

Lactobacillus johnsonii CRL1693, L. murinus CRL1695, L. mucosae CRL1696 and L. salivarius CRL1702 were used to elaborate the fermented milk. The strains were previously isolated from calf's faeces and selected by their beneficial properties [15]. Also, their resistance profiles to antibiotics were assayed [16] (Table 1). The microorganisms were stored in milk yeast extract $(13 \%$ skim milk, $0.5 \%$ yeast extract, $1 \%$ glucose) added with $20 \%$ glycerol at $-20^{\circ} \mathrm{C}$ up to use.

*Corresponding author: María E Fátima Nader-Macías, Chacabuco 145., 4000. Tucumán, Argentina, Tel: 54-381-431-1720 extn. 141; Fax: 54-381-400-5600 E-mail: fnader@cerela.org.ar

\section{Received April 04, 2016; Accepted April 24, 2016; Published April 29, 2016}

Citation: Maldonado NC, Nader-Macías MEF (2016) Production of Fermented Milk with Autochthonous Lactobacilli for Newborn Calves and Resistance to the Dairy Farm Conditions. J Bioprocess Biotech 6: 278. doi:10.4172/2155-9821.1000278

Copyright: @ 2016 Maldonado NC, et al. This is an open-access article distributed under the terms of the Creative Commons Attribution License, which permits unrestricted use, distribution, and reproduction in any medium, provided the original author and source are credited. 


\begin{tabular}{|c|c|c|c|c|c|}
\hline \multirow{2}{*}{ Strains } & \multirow{2}{*}{ Beneficial Properties } & \multicolumn{3}{|c|}{ Susceptibility profiles MICs ${ }^{1}(\mu \mathrm{g} / \mathrm{ml})$} & References \\
\hline & & AMP & CIP & VAN & \multirow{5}{*}[16,17]{} \\
\hline L. johnsonii CRL1693 & Hydrophobic and auto-aggregative & $<0.25$ & 8 & 0.5 & \\
\hline L. murinus CRL1695 & Auto-aggregative & 2 & 1 & $>128$ & \\
\hline L. mucosae CRL1696 & Peroxide production & $<0.25$ & 32 & $>128$ & \\
\hline L. salivarius CRL1702 & Hydrophobic & $<0.25$ & 2 & $>128$ & \\
\hline
\end{tabular}

${ }^{1} \mathrm{MICs}$ : Minimal Inhibitory concentrations: the lowest concentration of an antimicrobial that inhibited the visible growth of a microorganism after overnight incubation; AMP Ampicillin; CIP: Ciprofloxacin; VAN: Vancomycin

Table 1: Beneficial properties and susceptibility profiles of lactobacilli strains selected for the design of fermented milk for calves.

\section{Lactobacilli resistance to environmental conditions: Water, colostrum and raw milk}

Samples of water, raw milk and colostrum's pools (1,3 and 5 days after calving) were obtained in sterile conditions from different dams in a dairy farm in Trancas Department (Tucumán, Argentine). The samples were stored at $-20^{\circ} \mathrm{C}$ up to their use at laboratory. Before the experimental assays, they were defrosted and maintained at room temperature for one hour. Chlorination treatments were applied to water for animals' consumption, then the concentration of hypochlorite added was defined by the owners of the farm following standardized protocols of chlorination. Also, the initial lactic acid bacteria populations in raw milk and colostrum were determined.

The strains were subcultured twice in MRS (Merck, Damstadt, Germany) broth incubated for $16 \mathrm{~h}$ at $37^{\circ} \mathrm{C}$. The last sub-culture was used to perform the resistance studies. Then, the cells were harvested by centrifugation at $8000 \mathrm{rpm}$ for 15 minutes (5415D Eppendorf, USA), and washed with sterile saline solution. The pellets were resuspended in water, raw milk and colostrum (and in MRS broth as control) and incubated at $37^{\circ} \mathrm{C}$.

The number of viable cell was determined at the beginning of the incubation and after 2 and $4 \mathrm{~h}$ at room temperature. The viable cells were quantified by the serial dilution method in $0.1 \%$ peptone water and aliquots plated in MRS agar (by duplicate).

\section{Compatibility assays between strains}

The compatibility between the Lactobacillus strains was performed by using the plate diffusion technique described by Maldonado et al. [15] with brief modifications. Agar plates with indicator strains were inoculated with $10^{8} \mathrm{CFU}$. Culture supernatants were neutralized with sterile $1 \mathrm{~N} \mathrm{NaOH}$ to avoid the acidic effect of the supernatants to the cells in the fermented milk. An inhibition zone of at least $6 \mathrm{~mm}$ diameter was considered positive.

\section{Elaboration of the fermented milk}

Bacteria inoculation: The strains were inoculated into MRS broth and incubated for $24 \mathrm{~h}$ at $37^{\circ} \mathrm{C}$; then $(2 \%$ inoculum) were subcultured twice at $12 \mathrm{~h}$ and $16 \mathrm{~h}$ at $37^{\circ} \mathrm{C}$ in the same medium. The last sub-culture was used to inoculate milk. $500 \mathrm{ml}$ Low-fat milk (Milkaut, Santa Fe, Argentine) was sterilized for $12 \mathrm{~min}$ at $110^{\circ} \mathrm{C}$ by autoclaving (Rocker, Buenos Aires, Argentine) and stored at $4^{\circ} \mathrm{C}$ up to inoculation of the strains. The sterile milk bottles were kept at room temperature for 1 hour before the inoculation of microorganisms.

The four strains grown in MRS broth were used to inoculate the milk. One $\mathrm{mL}$ ( $2 \%$ inoculum) of each microorganism was added to 500 $\mathrm{ml}$ of milk and then incubated for 8,12 and $16 \mathrm{~h}$ at $37^{\circ} \mathrm{C}$. The fermented milk was stored later at $4^{\circ} \mathrm{C}$. The number of viable cells and $\mathrm{pH}$ were determined at the beginning of the inoculation and after 2,4 and $8 \mathrm{~h}$ by the serial dilution method as described before. Control was performed in MRS broth under the same conditions.

\section{Fermented milk storage and second fermentation process}

The viable bacteria number in the fermented milk was determined after $5,10,20$ and 30 days of storage at $4^{\circ} \mathrm{C}$ by using the agar plate technique described before. Control was performed with the strains in Saline. To define the number of viable microorganisms for older animals, $25 \mu$ of the product was inoculated in $2 \mathrm{ml}$ of raw milk for $2 \mathrm{~h}$ at room temperature. Refrigeration survival was determined after 2, 3 and 5 days (period of maintenance of milk in farm tanks before feeding calves). Viable cell numbers were determined throughout the experiment by the plate count technique.

\section{Maintenance of beneficial properties}

Quantification of lactobacilli by their growth in selective media: The strains were differentiated by their resistance profile to antibiotics [16] by using culture media added with different combination of antibiotics: Vancomycin (VAN) (Sigma-Aldrich, St Louis, USA), Ciprofloxacin (CIP) Sigma-Aldrich, St Louis, USA) and Ampicillin (AMP) (Trifacilina, Bagó, Argentine). Plates containing antibiotics were prepared by adding $1 \mathrm{ml}$ to $9 \mathrm{ml}$ MRS agar to reach a concentration of Vancomycin $(3.2 \mu \mathrm{g} / \mathrm{ml})+$ Ciprofloxacin $(6.4 \mu \mathrm{g} / \mathrm{ml})$ that support the growth of $L$. mucosae and Vancomycin $(3.2 \mu \mathrm{g} / \mathrm{ml})+$ Ampicillin $(1 \mu \mathrm{g} /$ $\mathrm{ml}$ ) for the growth of L. murinus.

After fermentation processes, dilutions of fermented milk were plated onto differential culture media with antibiotics. The plates were incubated for $48 \mathrm{~h}$ in microaerophylic conditions at $37^{\circ} \mathrm{C}$. One or two colonies were selected and grown in MRS broth for further studies.

\section{Maintenance of beneficial properties: Autoaggregation and hydrophobicity assays}

Hydrophobicity and auto-aggregation patterns of the strains were evaluated by the method described by Maldonado et al. [15]. Briefly, modifications of the optical density of cells in saline solution were monitored for 2 hours and the auto aggregation index calculated.

\section{Genetic identification of colonies}

The colonies grown in the differential cultured media and evaluated by their surface properties were later genetically identified according to Hébert et al. [17] by the $16 \mathrm{~S}$ ribosomal RNA gene sequencing.

\section{Statistical analysis}

The survival, elaboration and storage experiments were performed by duplicate. The analysis of variance in one way (one way ANOVA) was applied to determine the survival of the strains to dairy farm conditions (water, colostrum and raw milk) and the effect of water, raw milk and colostrum on the growth of the microorganisms was evaluated by Tukey's Test. Significant differences of the main effects of the strains, time and assay conditions on the growth were obtained from the number of viable cells data. 
Citation: Maldonado NC, Nader-Macías MEF (2016) Production of Fermented Milk with Autochthonous Lactobacilli for Newborn Calves and Resistance to the Dairy Farm Conditions. J Bioprocess Biotech 6: 278. doi:10.4172/2155-9821.1000278

Page 3 of 5

\section{Results}

\section{Resistance of the strains to environmental conditions: Water, colostrum and raw milk}

No significant differences were observed in the number of viable cells of $L$. mucosae, L. salivarius, $L$. murinus and $L$ johnsonii after incubation in raw milk and colostrum during two or four hours (Figure 1). The mean effects of the strain, time and condition under study on the growth were determined; no differences were obtained, except for L. johnsonii CRL1693 (Figure 2). The water resistance assays showed that all the strains maintained their viability (Figure 3).

\section{Compatibility of the strains}

L. johnsonii CRL1693, L. murinus CRL1695, L. mucosae CRL1696 and $L$. salivarius CRL1702 showed to be compatible between them, because there was no inhibition (Figure 4) in the agar plates, by using the strains both as indicators or producer strains.

\section{Elaboration of fermented milk}

Process applied to prepare the fermented milk: The final flow chart applied for the elaboration of the probiotic fermented milk and the further administration to calves is summarized in Figure 5. Four strains of lactobacilli were used to inoculate milk (A in flow chart). The final inoculum of each strain was: Lactobacillus johnsonii CRL1693 6.6 $\times 10^{7} ;$ L. murinus CRL1695 $1.17 \times 10^{9} ;$ L. mucosae CRL1696 $2.04 \times 10^{9}$ and L. salivarius CRL1702 $1.09 \times 10^{9}$.

The optimal fermentation time was 8 hours, because longer incubation times (12 or $16 \mathrm{~h}$ ) produced a coagulation of the milk, which is not adequate to feed calves (B in flow chart). The number of viable lactobacilli and milk $\mathrm{pH}$ during the process is plotted in Figure 6.

\section{Storage and administration to older animals}

The survival of the strains was evaluated for 30 days obtaining similar viable cell numbers during the period, as shown in Figure 7 (C in flow chart), with a lower number of bacteria in control maintained

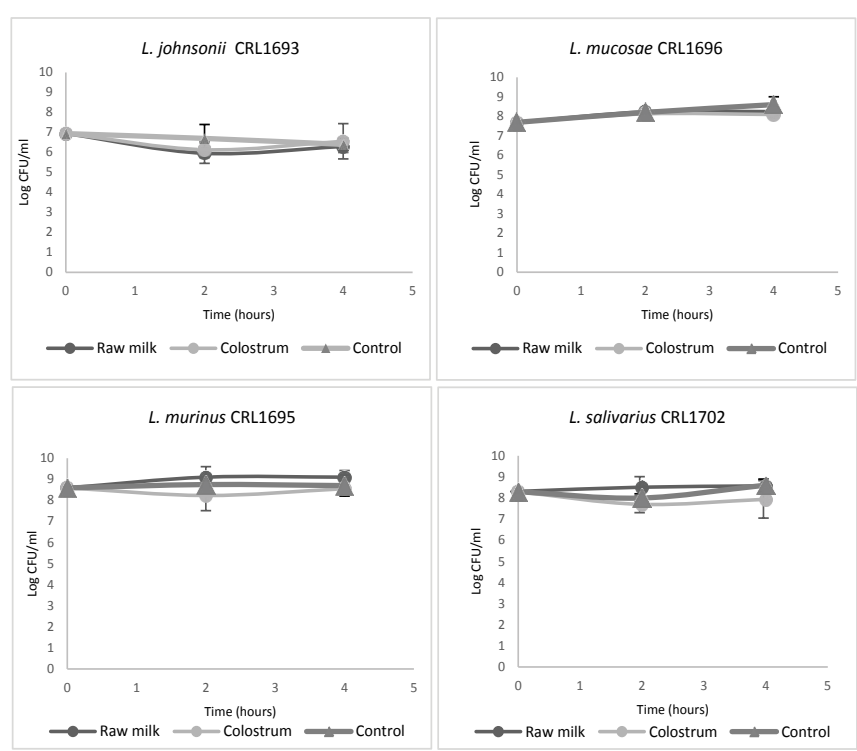

Figure 1: Resistance of lactobacilli strains to dairy farm conditions: bacteria survive to Colostrum and Raw Milk after $4 \mathrm{~h}$ incubation. The strains in MRS broth were used as control.

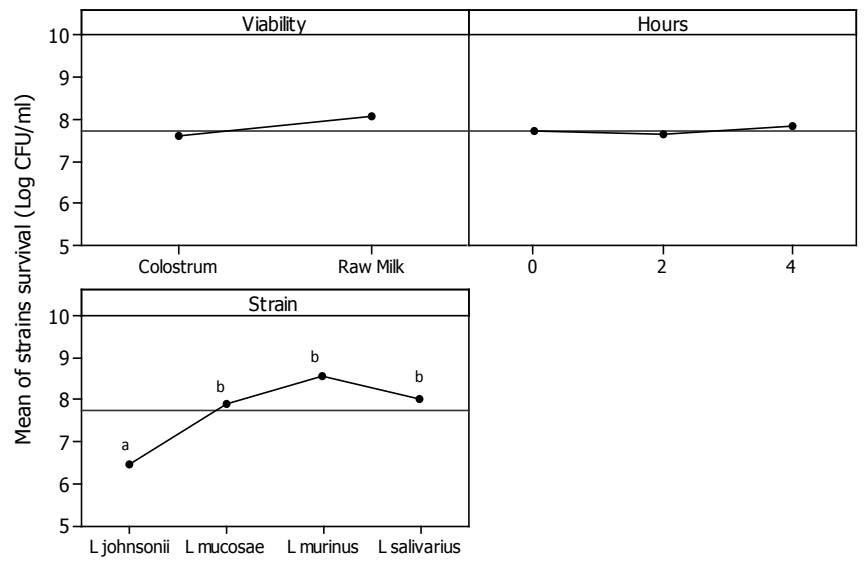

Figure 2: Main Effects Plots obtained from Minitab software, indicating the main effects of each one of the factors under study on the bacteria compatibility. The points represent the mean of all the experimental data: number of viable bacteria in Raw Milk or Colostrum, time of incubation, or number of viable bacteria of each strain. The line represents the tendency of the results. Different letters indicate statistical differences as determined by an ANOVA/Tukey's test $(p<0.05)$ using data means

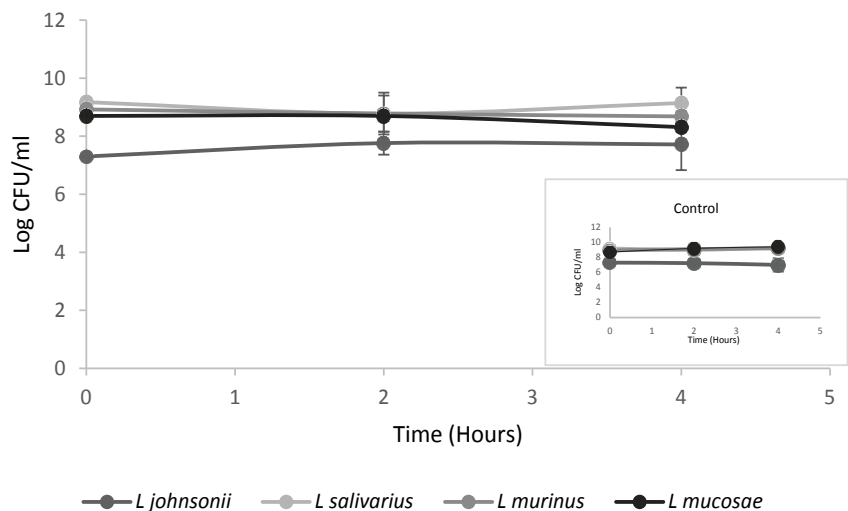

Figure 3: Resistance of lactobacilli to dairy farm conditions: bacteria survival to water. The strains in MRS broth were used as control.

in saline, indicating some type of protective effect of the milk on the viability of the strains.

The fermented milk will be administered to newborn animals by using a syringe delivering $10 \mathrm{ml} /$ day directly in the oral cavity (E). For older animals, the fermented milk will be administered from buckets, "ad libitum" (F). Therefore, $500 \mathrm{ml}$ of fermented milk will be used to inoculate 40 liters raw milk in storage tanks, and incubated at room temperature for $2 \mathrm{~h}$. For this second fermentation stage, the number of viable cells was $2.88 \times 10^{6} \mathrm{CFU} / \mathrm{ml}$. The milk $\mathrm{pH}$ was 6.59 at the beginning of the fermentation and 5.98 after incubation. Then, in the refrigerated tank, the bacteria showed to maintain similar numbers during five days. No differences in the viable cells numbers were observed during the storage (Figure 8). Considering that the older animals (three months age) drink around 4 liters/day, the number of viable bacteria that will be administered to young and old animals will be similar.

\section{Maintenance of beneficial properties}

The surface properties of the strains were maintained during the storage: L murinus CRL1695 showed the high auto-aggregating 


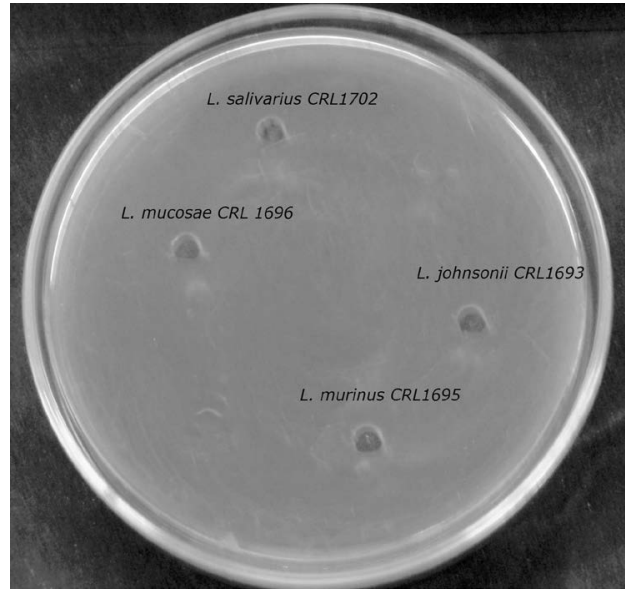

Figure 4: Compatibility of the strains by the agar plate diffusion method. Each one of the Lactobacillus strain was used both as an indicator (included into the agar plate) and as a producer of inhibitory substances (supernatant of liquid culture). The picture shows only when $L$. salivarius was used as indicator strain. The supernatant of L. johnsonii CRL1693, L. murinus CRL1695, L. mucosae $C R L 1696$ and $L$. salivarius CRL1702 did not inhibited the growth of the other strains, and as shown in this picture, to $L$. salivarius.

characteristic, while L. mucosae CRL1696 maintained the hydrophobicity. L murinus CRL1695 auto-aggregation index was 68 $\pm 5 \%$ and the hydrophobic index $15 \pm 3 \%$. For L. murinus CRL1695, a value of $25 \pm 2 \%$ auto-aggregation index was obtained, and also a hydrophobic pattern. The four strains were later grown in media with antibiotics and identified by and genetic techniques.

\section{Discussion}

The intensive management systems applied in dairy farms reduce the period of lactation in calves, and produce some disequilibrium of the Gastrointestinal Tract (GIT) microbiota, and in some situations, frequent diarrhoea [18]. Our research group has been working in the design of a probiotic product with autochthonous lactobacilli for calves. Some authors have described that young animals prefer liquid feed [19] then we decided to go further in the design of liquid fermented milk to fit with these preferences. A common procedure in dairy farms is the administration of raw milk to new born calves, being a cause of frequent diarrhoea [20]. In this context, the administration of fermented milk containing a high number of lactic acid bacteria is proposed, that could favour the inhibition of pathogens in raw milk, supported by the inhibitions evidenced previously [15]. Other cause for young calves' diarrhoea is the exposition to a contaminated environment, and then if the pathogen colonization of this environment is reduced by the lactic acid bacteria included in the fermented milk, it could be an adequate alternative to reduce its occurrence [20]. It has been proposed that the administration of fermented milk will increase the colonization of lactic bacteria in the farm (pens, soil, feeding utensils) after the treatments. Then, we are performing experiments with administration of fermented milk in small tanks to 2 to 3 months calves.

Probiotic administration to calves can be proposed from the first days of life when they receive colostrum's from their mothers. According to our results, the immune properties and antibacterial effect of colostrum do not affect the lactobacilli strains included in the fermented milk. As the colostrum quality depends on the immunoglobulin's concentration (affected by the dam condition and time after calving) a pool of colostrum was assayed Champagne et al. have shown that bovine colostrum could promote the growth of some probiotic bacteria and inhibit intestinal pathogens such as E. coli. [21], and also could be used for the design of a combined product.

The survival of the beneficial strains in the conditions studied in this work, and the number of viable cells obtained after the fermentation process is higher than the minimum level suggested $\left(10^{7}\right.$ $\mathrm{cfu} / \mathrm{ml}$ ) for a probiotic product. Also, the viability of the bacterial cells was maintained during 30 days that is the regular shelf life of most of the dairy fermented products. Donnet-Hughes et al. [22] observed that lower daily dose of $10^{8} \mathrm{cfu} / \mathrm{d}$ of $L$. johnsonii LA1 produced no significant effect in contrast with a daily dose of $10^{9} \mathrm{cfu} / \mathrm{d}$ that modulate defense mechanisms in humans. Considering a daily consumption of fluid fermented dairy products is around 41 in 2 to 3 months age animals, while an oral administration of $10 \mathrm{ml}$ fermented milk is given to newborns calves, the product or formula should contain between $10^{6} \mathrm{CFU} / \mathrm{ml}$ to $10^{9} \mathrm{CFU} / \mathrm{ml}$ bacteria, viable cells numbers obtained in this work. Experimental animal's assays are being performed in order to evaluate the beneficial properties of the designed fermented milk in calves and the prevention of calves' diarrhea.

\section{Acknowledgements}

This work was supported by PICT 1187 from ANPCYT (Agencia Nacional de Promoción Científica y Tecnológica Agencia, Argentine) and PIP 0744 from CONICET (Consejo Nacional de Investigaciones Científicas y Técnicas, Argentine)
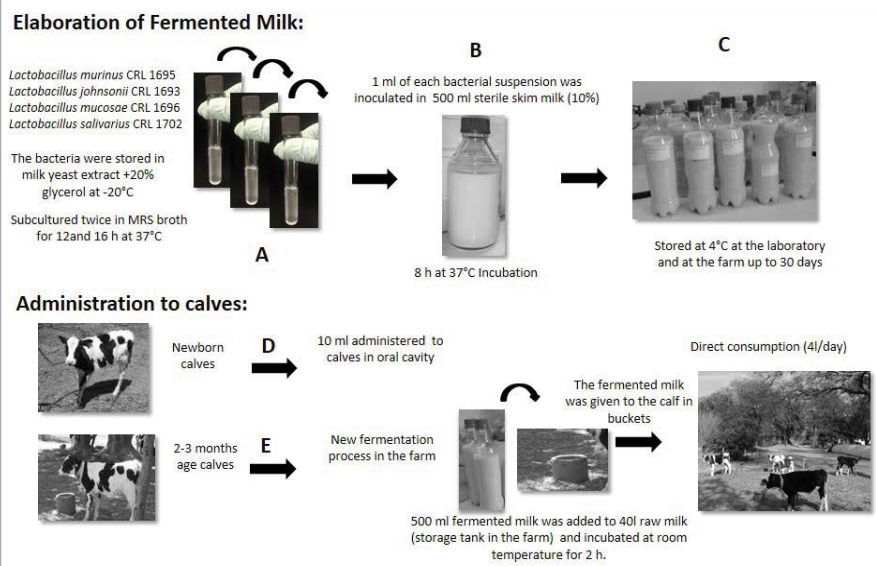

Figure 5: Flow chart showing all the stages applied for the elaboration and administration of fermented milk to calves.

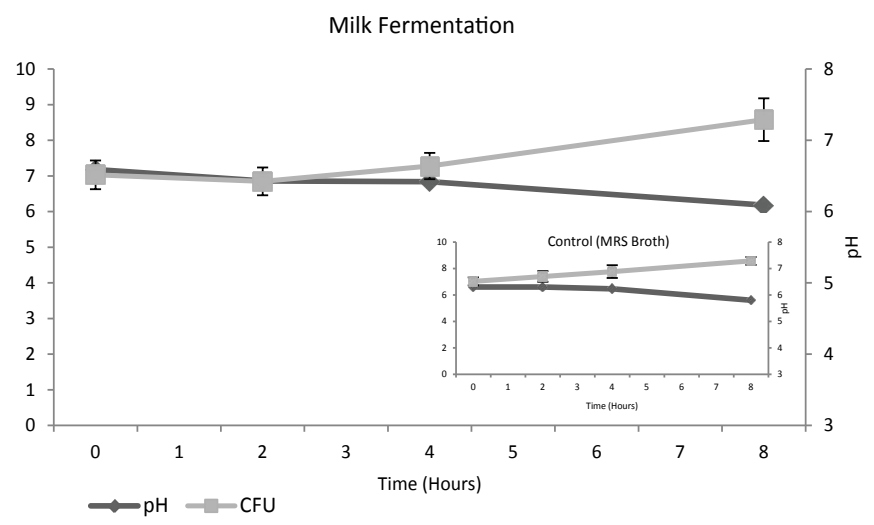

Figure 6: Bacteria cells counts during fermentation at $37^{\circ} \mathrm{C}$ for eight hours and modifications of the milk $\mathrm{pH}$. Control indicates the growth of the strains in MRS broth. 
Citation: Maldonado NC, Nader-Macías MEF (2016) Production of Fermented Milk with Autochthonous Lactobacilli for Newborn Calves and Resistance to the Dairy Farm Conditions. J Bioprocess Biotech 6: 278. doi:10.4172/2155-9821.1000278

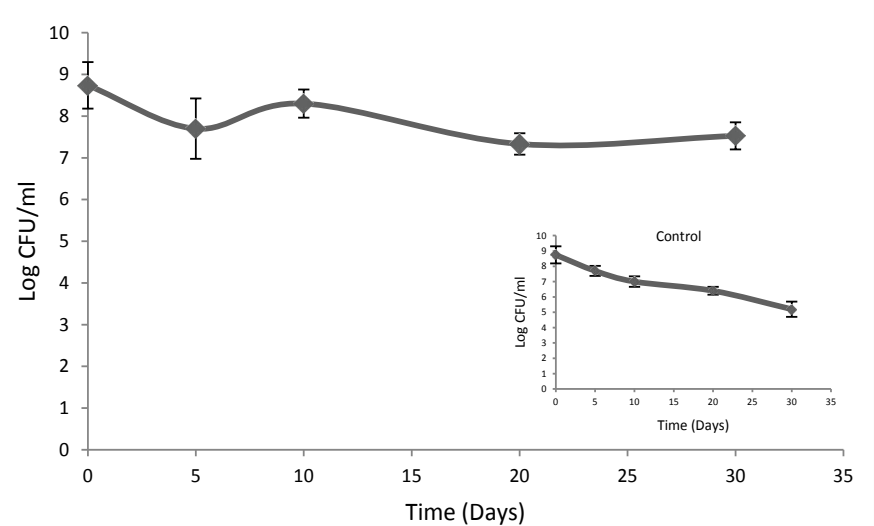

Figure 7: Storage of fermented milk for 30 days at refrigeration temperature.a

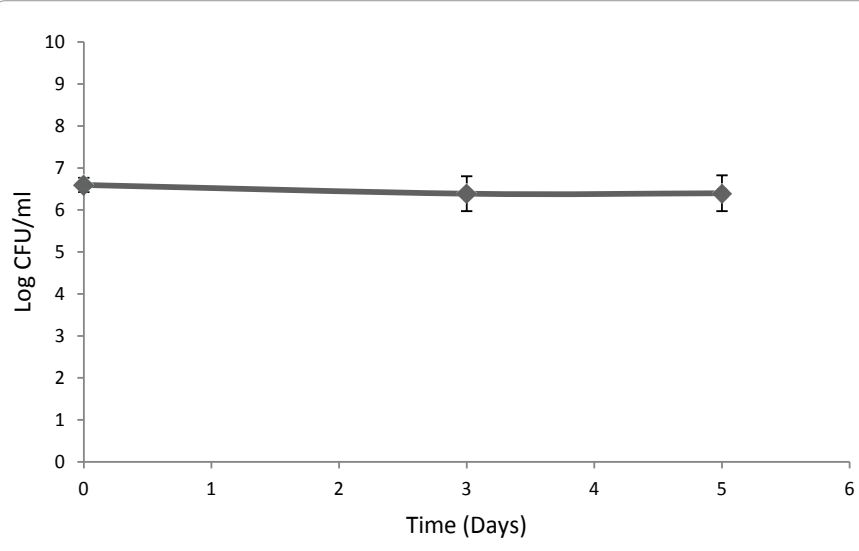

Figure 8: Storage of milk in the farm after second fermentation for 2-3 months age calves during five days at refrigeration temperature.

The strains were included in a patent "Leche fermentada y/o tratamiento de las infecciones intestinales en terneros y procedimientos". INPI (Instituto Nacional de la Propiedad Intelectual, Argentine). №20150102316- Date: 21/07/2015.

\section{References}

1. Murray CF, Leslie KE (2013) Newborn calf vitality: risk factors, characteristics, assessment, resulting outcomes and strategies for improvement. Vet J 198: 322-328.

2. Moran J (2012) Rearing Young Stock on Tropical Dairy Farms in Asia. The importance of colostrum to newborn calves. CSIRO Publishing.

3. Uetake K (2013) Newborn calf welfare: a review focusing on mortality rates. Anim Sci J 84: 101-105.

4. Silbergeld EK, Graham J, Price LB (2008) Industrial food animal production, antimicrobial resistance, and human health. Annu Rev Public Health 29: 151-169.

5. Thormar H (2012) Patented non-antibiotic agents as animal feed additives. Recent Pat Food Nutr Agric 4: 155-168.

6. Reid G, Sanders ME, Gaskins HR, Gibson GR, Mercenier A, et al. (2003) New scientific paradigms for probiotics and prebiotics. J Clin Gastroenterol 37: 105-118.

7. Gaggìa $F$, Mattarelli $P$, Biavati $B(2010)$ Probiotics and prebiotics in animal feeding for safe food production. Int J Food Microbiol 141 Suppl 1: S15-28.

8. Zhang R, Zhou M, Tu Y, Zhang NF, Deng KD, et al. (2016) Effect of ora administration of probiotics on growth performance, apparent nutrient digestibility and stress-related indicators in Holstein calves. J Anim Physio Anim Nutr (Berl) 100: 33-38.

9. Timmerman HM, Mulder L, Everts H, van Espen DC, van der Wal E, et al. (2005) Health and growth of veal calves fed milk replacers with or without probiotics. J Dairy Sci 88: 2154-2165.
10. Unno T, Choi JH, Hur HG, Sadowsky MJ, Ahn YT, et al. (2015) Changes in human gut microbiota influenced by probiotic fermented milk ingestion. J Dairy Sci 98: 3568-3576.

11. Azuma $Y$, Ito $K$, Ohki A, Inoue A, Inoue K, et al. (2001) Effects of a milk drink fermented with Lactobacillus gasseri NY0509 and Lactobacillus casei NY1301 on fecal microflora in healthy volunteers. Nippon Shokuhin Kagaku Kogaku Kaishi 48: 35-43.

12. Hekmat S, Soltani H, Reid G (2009) Growth and survival of Lactobacillus reuter RC-14 and Lactobacillus rhamnosus GR-1 in yogurt for use as a functional food. Innov Food Sci Emerg Technol 10: 2932-2936.

13. Vanderhoof JA, Young RJ (1998) Use of probiotics in childhood gastrointestinal disorders. J Pediatr Gastroenterol Nutr 27: 323-332.

14. Ross RP, Desmond C, Fitzgerald GF, Stanton C (2005) Overcoming the technological hurdles in the development of probiotic foods. J Appl Microbio 98: 1410-1417.

15. Maldonado NC, de Ruiz CS, Otero MC, Sesma F, Nader-Macías ME (2012) Lactic acid bacteria isolated from young calves--characterization and potential as probiotics. Res Vet Sci 92: 342-349.

16. Maldonado NC, Nader-Macías F (2015) Functional Properties (Acid and Bile Tolerance) and Antibiotic Susceptibility of Lactic Acid Bacteria Isolated from Newborn Calves for the Design of a Probiotic Product. Inter J Vet Sci Res 1 : 11-22.

17. Hébert EM, Raya RR, Tailliez P, de Giori GS (2000) Characterization of natural isolates of Lactobacillus strains to be used as starter cultures in dairy fermentation. Int J Food Microbiol 59: 19-27.

18. Eckert E, Brown HE, Leslie KE, DeVries TJ, Steele MA (2015) Weaning age affects growth, feed intake, gastrointestinal development, and behavior in Holstein calves fed an elevated plane of nutrition during the preweaning stage. J Dairy Sci 98: 6315-6326.

19. Klein-Jöbstl D, Arnholdt T, Sturmlechner F, Iwersen M, Drillich M (2015) Results of an online questionnaire to survey calf management practices on dairy cattle breeding farms in Austria and to estimate differences in disease incidences depending on farm structure and management practices. Acta Vet Scand 57: 44.

20. Cho YI, Yoon KJ (2014) An overview of calf diarrhea - infectious etiology, diagnosis, and intervention. $J$ Vet Sci 15: 1-17.

21. Champagne CP, Raymond Y, Pouliot Y, Gauthier SF, Lessard M (2014) Effect of bovine colostrum, cheese whey, and spray-dried porcine plasma on the in vitro growth of probiotic bacteria and Escherichia coli. Can J Microbiol 60: 287 295.

22. Donnet-Hughes A, Rochat F, Serrant P, Aeschlimann JM, Schiffrin EJ (1999) Modulation of nonspecific mechanisms of defense by lactic acid bacteria: effective dose. J Dairy Sci 82: 863-869.

Citation: Maldonado NC, Nader-Macias MEF (2016) Production of Fermented Milk with Autochthonous Lactobacilli for Newborn Calves and Resistance to the Dairy Farm Conditions. J Bioprocess Biotech 6: 278. doi:10.4172/21559821.1000278 